\title{
Longterm Safety, Efficacy, and Inhibition of Structural Damage Progression Over 5 Years of Treatment with Abatacept in Patients with Rheumatoid Arthritis in the Abatacept in Inadequate Responders to Methotrexate
} Trial

\author{
Joel M. Kremer, Charles Peterfy, Anthony S. Russell, Paul Emery, Carlos Abud-Mendoza, \\ Jean Sibilia, Jean-Claude Becker, Rene Westhovens, and Harry K. Genant
}

\begin{abstract}
Objective. Evaluate the safety and efficacy of longterm abatacept (ABA) treatment over 5 years in methotrexate (MTX)-refractory patients with rheumatoid arthritis (RA).

Methods. Patients from the 1-year, double-blind Abatacept in Inadequate Responders to Methotrexate (AIM) study (NCT00048568) received open-label ABA $(\sim 10 \mathrm{mg} / \mathrm{kg})$ in the longterm extension (LTE). Safety was assessed for patients who received $\geq 1$ ABA dose, and efficacy for patients randomized to ABA and treated in the LTE. Radiographs were evaluated for changes in Genant-modified Sharp scores.

Results. Out of 652 patients, 539 entered the LTE (ABA, $n=378$; placebo, $n=161$ ). At Year 5, $72.4 \%$ were ongoing; discontinuation rates declined over time. Incidence rates of serious adverse events, serious infections, malignancies, and autoimmune events were 13.87, 2.84, 1.45, and 0.99 events/100 patient-years exposure, respectively. American College of Rheumatology 20 response was $82.3 \%(\mathrm{n}=373)$ and $83.6 \%(\mathrm{n}=268)$ at years 1 and 5 , respectively. Disease Activity Score 28 C-reactive protein (DAS28-CRP) $<2.6$ and $\leq 3.2$ were achieved by $25.4 \%$ and $44.1 \%$ of patients at Year $1(\mathrm{n}=370)$, and $33.7 \%$ and $54.7 \%$ at Year $5(\mathrm{n}=267)$, respectively. Mean changes in DAS28-CRP and Health Assessment Questionnaire-Disability Index at Year $1[-2.83(\mathrm{n}=365)$ and $-0.68(\mathrm{n}=369)]$ were maintained at Year $5[-3.14(\mathrm{n}=264)$ and $-0.77(\mathrm{n}=271)]$ for patients continuing treatment. Of them, 59.5\% $(\mathrm{n}=291)$ and $45.1 \%(\mathrm{n}=235)$ remained free from radiographic progression at years 1 and 5, respectively.

Conclusion. In MTX-refractory patients with RA, longterm ABA treatment was well tolerated and provided consistent safety and sustained efficacy, with high patient retention. Radiographic progression continued to be inhibited with ongoing treatment. (First Release May 1 2014; J Rheumatol 2014;41:1077-87; doi:10.3899/jrheum.130263)
\end{abstract}

Key Indexing Terms:

ABATACEPT

RHEUMATOID ARTHRITIS

METHOTREXATE

From the Center for Rheumatology, Albany Medical College, Albany, New York; Spire Sciences Inc., Boca Raton, Florida, USA; Division of Rheumatology, University of Alberta Hospital, Edmonton, Alberta, Canada; Division of Rheumatic and Musculoskeletal Disease, Leeds Institute of Molecular Medicine, University of Leeds; UK National Institute for Health Research (NIHR) Leeds Musculoskeletal Biomedical Research Unit, Leeds Teaching Hospitals Trust, Leeds, UK; Regional Unit of Rheumatology, Faculty of Medicine and Central Hospital, University of San Luis Potosí, San Luis Potosí, México; Service de Rhumatologie, CHU de Strasbourg, Hôpital de Hautepierre, Strasbourg, France; Bristol-Myers Squibb, Princeton, New Jersey, USA; Department of Rheumatology,

Universitaire Ziekenhuizenn Leuven, Leuven, Belgium; UCSF/Synarc, San Francisco, California, USA.

Professional medical writing and editorial assistance funded by Bristol-Myers Squibb, Princeton, New Jersey, USA, and provided by Eve Guichard BSc (hons) of Caudex Medical, Oxford, UK.

J.M. Kremer, MD, Center for Rheumatology, Albany Medical College; C. Peterfy, MD, PhD, FRCPC, Spire Sciences Inc.; A.S. Russell, FRCP,
FRCPC, Division of Rheumatology, University of Alberta Hospital; P. Emery, MA, MD, FRCP, FRCPE, Division of Rheumatic and Musculoskeletal Disease, Leeds Institute of Molecular Medicine, University of Leeds, and NIHR Leeds Musculoskeletal Biomedical Research Unit, Leeds Teaching Hospitals Trust; C. Abud-Mendoza, MD, Regional Unit of Rheumatology, Faculty of Medicine and Central Hospital, University of San Luis Potosí; J. Sibilia, MD, Service de Rhumatologie, CHU de Strasbourg, Hôpital de Hautepierre; J-C. Becker, $M D$, Bristol-Myers Squibb*; R. Westhovens, MD, Department of Rheumatology, Universitaire Ziekenhuizenn Leuven; H.K. Genant, MD, UCSF/Synarc.

*Affiliation at time of study.

Address correspondence to Dr. J.M. Kremer, Center for Rheumatology, Albany Medical College, 1367 Washington Ave., Albany, New York 12206, USA.E-mail: jkremer@joint-docs.com

Full Release Article. For details see Reprints/Permissions at jrheum.org Accepted for publication February 28, 2014.

Personal non-commercial use only. The Journal of Rheumatology Copyright $\subset$ C 2014. All rights reserved. 
Markedly improved treatment outcomes have been achieved in rheumatoid arthritis (RA) following the introduction of biologic therapy. As a result, patients with RA are now likely to receive biologics for a longer duration over the course of their disease. Given these changes in management practice, biologic therapies need to be well tolerated over the long term, and to provide sustainable and meaningful radiographic and clinical benefits. Combined recommendations from the European League Against Rheumatism/American College of Rheumatology (ACR) state the importance of simultaneously reporting multiple measures of disease activity, including the achievement of remission, low disease activity, and improvements in physical function in response to treatment; these guidelines also highlight the importance of reporting the sustainability of treatment responses ${ }^{1}$. A challenge with current therapies is to improve patient retention and sustainability of treatment response.

Abatacept (ABA), a T cell costimulation modulator, has demonstrated significant improvements in clinical efficacy and physical function, and has been shown to significantly reduce the progression of structural damage in 1-year, blinded, randomized, placebo-controlled trials of patients with established RA and an inadequate response to methotrexate (MTX) ${ }^{2,3,4}$. Further, ABA has been shown to be well tolerated, with a favorable safety profile in these studies.

Evidence suggests that improvements in clinical efficacy gained in the short term with ABA in patients with an inadequate response to MTX are sustained with continued longterm treatment, up to 5 years in a phase IIb study, with consistent safety with increasing exposure ${ }^{5,6,7,8}$. Further, persistent inhibition of the progression of structural damage with continued treatment has been observed for up to 3 years ${ }^{6,9}$.

Here, we report the 5-year findings from the AIM (Abatacept in Inadequate responders to Methotrexate) trial, the largest phase III trial to date of intravenous (IV) ABA in patients with RA and an inadequate response to MTX, to evaluate the effect of ABA on safety and tolerability, clinical efficacy, and structural damage progression over the long term.

\section{MATERIALS AND METHODS}

Study design. The design and conduct of the AIM trial and longterm extension (LTE; ClinicalTrials.gov identifier: NCT00048568) have been reported $^{3,5,6}$. In brief, AIM included a 1-year, double-blind (DB), placebo-controlled period, in which patients with active RA and an inadequate response to MTX were randomized in a 2:1 ratio to either ABA $(\sim 10$ $\mathrm{mg} / \mathrm{kg}$, according to weight range) or placebo, both plus MTX. Patients who completed the 1-year DB period were eligible to enter an open-label LTE.

All patients who completed the DB period (both ABA plus MTX and placebo plus MTX groups) and enrolled in the LTE received ABA at a dose of $\sim 10 \mathrm{mg} / \mathrm{kg}$, according to weight range, in addition to background MTX, every 28 days. MTX was administered at a dosage of at least $15 \mathrm{mg} /$ week $(10 \mathrm{mg} /$ week was permitted if the patient had previously experienced MTX toxicity). During the LTE, adjustments to MTX dose and other background nonbiologic disease-modifying antirheumatic drugs (DMARD) were permitted at the discretion of the investigator.

Safety assessments. Safety assessments were performed monthly and included monitoring of all reported adverse events (AE), serious AE (SAE), and treatment discontinuations due to $\mathrm{AE}$, which were classified according to the Medical Dictionary for Regulatory Activities (MedDRA). Autoimmune events and acute infusional AE (those occurring within $1 \mathrm{~h}$ of the start of infusion) were prespecified based on a list of MedDRA preferred terms

Clinical assessments. Prespecified efficacy assessments were performed quarterly during the LTE, until Year 4 of the study, and at 6-month intervals thereafter. Signs and symptoms of RA were assessed by ACR 20, 50, and 70 criteria $^{10}$, and are presented as the proportion $(95 \% \mathrm{CI})$ of patients achieving the response. Improvements in disease activity were evaluated using the 28-joint Disease Activity Score (DAS28), based on C-reactive protein (CRP) levels, and recorded as mean change from baseline. The proportion of patients achieving DAS28-CRP criteria of $\leq 3.2$ and $<2.6$ was evaluated ${ }^{11}$. Mean change from baseline in Health Assessment Questionnaire-Disability Index (HAQ-DI) was used to assess physical function ${ }^{12}$

In a posthoc analysis to evaluate the sustainability of treatment response at the patient level, the proportions of patients achieving different outcomes [ACR responses, DAS28 criteria, HAQ-DI normalization (defined as a HAQ-DI score $<0.5$ ), and radiographic nonprogression] at Year 1 and sustaining these responses at later timepoints (years 2, 3, 4, and 5 ) were assessed; data are summarized as the proportion of patients with $95 \% \mathrm{CI}$. A posthoc assessment of the proportion of patients simultaneously achieving multiple measures of efficacy was performed to evaluate clinical and functional outcomes for patients experiencing a treatment response defined by ACR response. The proportions of patients achieving both an ACR 50 response and DAS28-CRP $<2.6$, or ACR 50 and HAQ normalization were evaluated for yearly timepoints.

Radiographic assessments. Radiographs of the hands/wrists and feet were collected at baseline and at the end of years $1-5$, or on early termination. Radiographs from baseline and years 1-5, for patients in the LTE period, were reexamined at Year 5 by independent radiologists who were blinded to the treatment group assignments, chronological order, clinical response, and previous radiographic results (Synarc).

Mean changes from baseline in erosion scores (ES), joint-space narrowing (JSN), and total scores (TS) were assessed using the Genant-modified Sharp scoring method ${ }^{9,13}$, which gives a maximum possible TS for both hands and feet of 290 . The proportion $(95 \%$ CI) of patients with no radiographic progression, defined as a change from baseline in TS of $\leq 0$, was evaluated at each year. Posthoc analyses were performed to determine the proportion of patients who remained free from radiographic progression year on year.

Statistical analyses. Baseline demographic data and clinical characteristics were analyzed descriptively for patients entering the LTE. Safety was evaluated for all patients who received at least 1 dose of ABA during the LTE, irrespective of their treatment group during the DB period; events are reported as frequencies and incidence rates (IR). For patients originally assigned to placebo plus MTX, AE were included in the analyses only if they occurred during the LTE period, while patients were receiving ABA therapy. Safety was evaluated based on events that occurred up to 56 days following the last dose of the study drug during the LTE.

IR were calculated as the number of patients with the event of interest, divided by the total exposure during the specified treatment period, multiplied by 100 to provide the events/100 patient-years of exposure. A patient's contribution to exposure (patient-yrs) ended at the time of first occurrence of the specific AE (therefore repeat occurrences of the same event, if they occurred, were not included). IR are presented for the DB period (patients randomized to $\mathrm{ABA}$ ) and for the cumulative period (patients who received at least 1 dose of $\mathrm{ABA}$ at any time).

Personal non-commercial use only. The Journal of Rheumatology Copyright $\subset$ 2014. All rights reserved. 
Efficacy and radiographic assessments, including posthoc analyses, are presented for all patients who were originally randomized to the ABA group during the DB period and later entered the LTE, and had data available at the visit of interest (as-observed). The study design was not initially powered for the posthoc analyses presented here.

\section{RESULTS}

Patient disposition. A total of 652 patients (ABA plus MTX, $\mathrm{n}=433$; placebo plus MTX, $\mathrm{n}=219$ ) were randomly assigned to treatment in the DB period of the AIM trial. After completing the 1-year DB period, 539 patients (ABA plus MTX, $\mathrm{n}=378$; placebo plus MTX, $\mathrm{n}=161$ ) entered the LTE, with $390(72.4 \%)$ patients continuing at the end of Year 5 (Figure 1A). For patients originally randomized to ABA, 70.4\% (266/378) of the patients who entered the LTE

A)

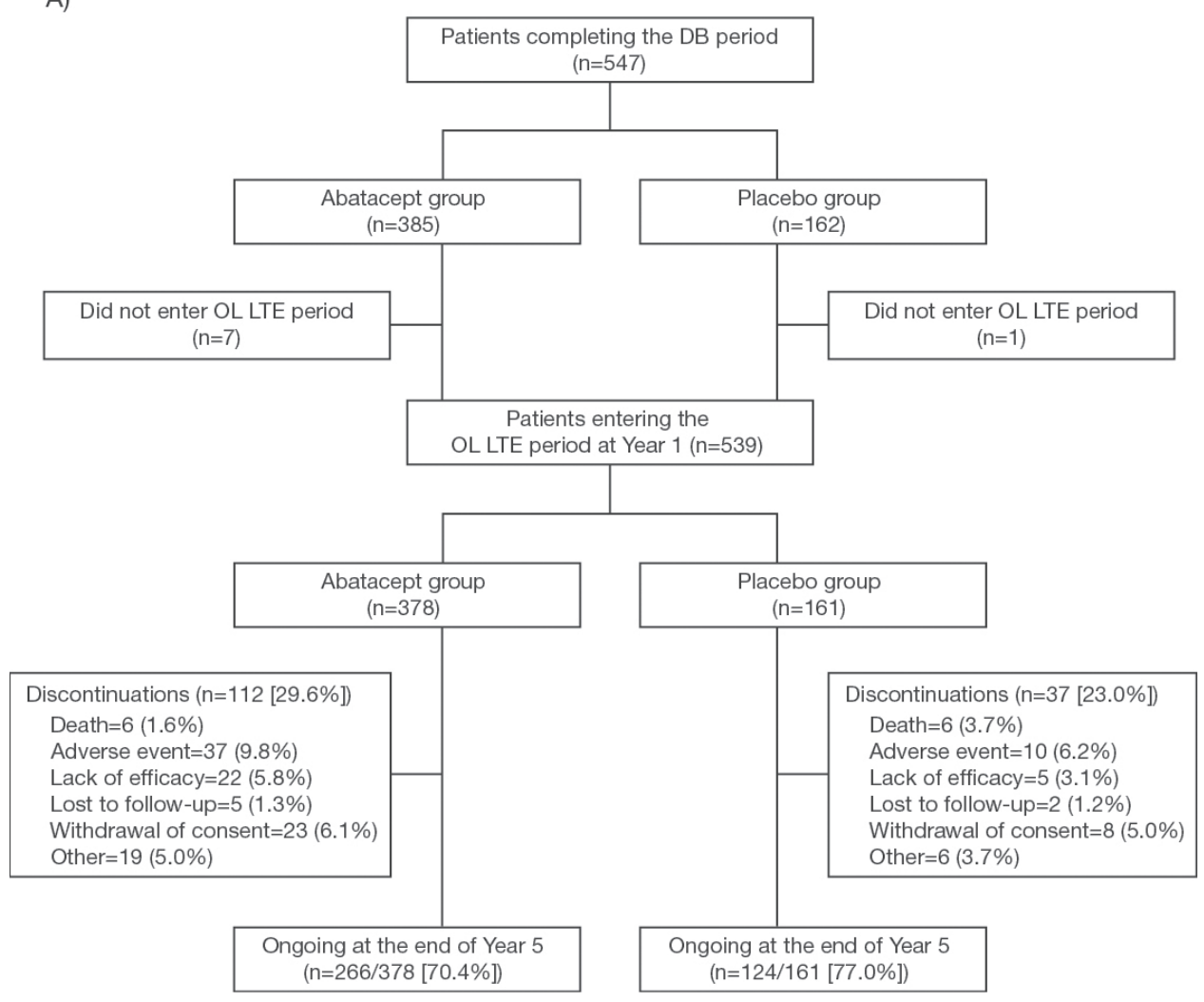

B)

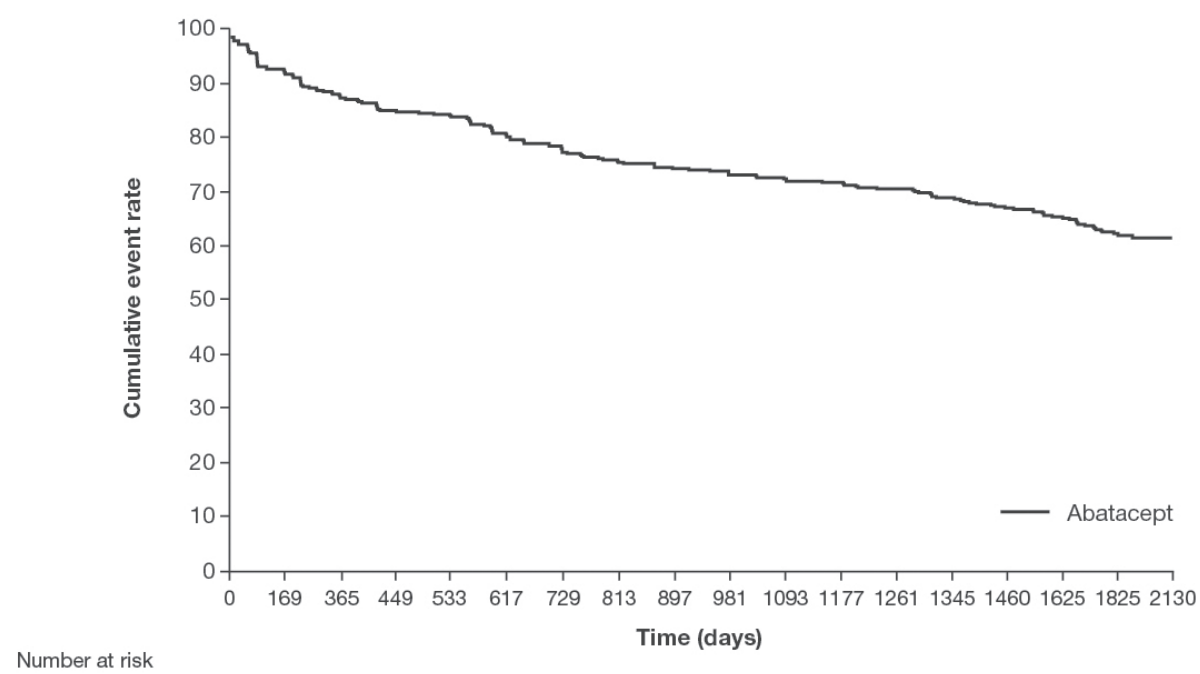

Figure 1. (A) Disposition and (B) retention of patients in the AIM trial. DB: double blind; LTE: longterm extension; OL: open label. 
were continuing at Year 5 of the study. The numbers and rates of patients discontinuing treatment generally decreased throughout the study: $48 / 433$ (11.1\%), 46/378 (12.2\%), $21 / 332(6.3 \%), 22 / 311(7.1 \%)$, and $23 / 289(8.0 \%)$ during years $1-5$, respectively, as is highlighted in the Kaplan-Meier survival graph of retention (Figure 1B).

During the LTE, 22 of 378 patients (5.8\%) originally randomized to ABA discontinued because of lack of efficacy and 37 of 378 (9.8\%) because of AE (Figure 1A). Discontinuation rates for lack of efficacy at years 2-5 were $2.4 \%$ (9/378), $0.9 \%$ (3/332), $1.6 \%(5 / 311)$, and $1.7 \%$ (5/289), respectively, and for AE were 4.0\% (15/378), $1.5 \%$ (5/332), 3.2\% (10/311), and 2.4\% (7/289), respectively.

Baseline demographics and clinical characteristics. Demographics and clinical characteristics at randomization for patients who entered the LTE have been reported, and were comparable between original treatment groups and similar to patients in the DB period ${ }^{2,8}$. Patients had a mean (SD) age of 50.8 years (12.4) and a disease duration of 8.5 years (7.2). Baseline disease activity was high: DAS28-CRP of 6.3 (0.8), 31.6 (13.3) tender joints, and 21.9 (8.8) swollen joints, and a HAQ-DI score of 1.7 (0.6).

Of the original ABA-treated patients who entered the LTE, 293 had radiographs available at both baseline and another timepoint and were included for analysis. These patients had evidence of structural damage prior to ABA treatment, as assessed by baseline Genant-modified Sharp scores - TS: 28.5 (28.9), ES: 17.7 (15.8), and JSN: 10.8 (14.0).

Concomitant medication. Changes in MTX and steroid doses were permitted from Month 6 of the study. For patients originally randomized to ABA, mean MTX doses were $15.1 \mathrm{mg}$ at baseline, and 14.4, 14.3, 14.2, 14.3, and $14.4 \mathrm{mg}$ at years $1-5$, respectively. All patients were receiving MTX at the start of the LTE. Overall, 7.1\% (27/378) of patients originally randomized to ABA completely discontinued concomitant MTX treatment during the study $(0 \%, 3.7 \%, 1.3 \%, 1.3 \%$, and $0.8 \%$ at yrs $1-5$, respectively). During the study, MTX dose was increased compared to the previous year in 40/378 patients $(10.6 \%)$ in Year 2, 50/359 (13.9\%) in Year 3, 43/351 $(12.3 \%)$ in Year 4, and 45/343 (13.1\%) in Year 5 among those originally randomized to ABA. Addition of other nonbiologic DMARD was permitted from Month 6, with $12.2 \%$ of patients originally randomized to ABA adding another DMARD during the course of the study (4.0\%, $2.6 \%, 0.8 \%, 2.4 \%$, and $2.4 \%$ at yrs $1-5$, respectively). Mean steroid dose in patients originally randomized to ABA was $6.7 \mathrm{mg}$ at baseline, and 6.7, 5.9,6.7, and $6.0 \mathrm{mg}$ at years 1 , 2,3 , and 5, respectively; overall, $15.1 \%$ (57/378) of patients completely discontinued steroids during the study $(2.1 \%$, $2.9 \%, 4.2 \%, 1.9 \%$, and $4.0 \%$ at yrs $1-5$, respectively), and $11.1 \%(42 / 378)$ initiated concomitant steroid treatment $(5.0 \%, 2.1 \%, 2.6 \%, 0.5 \%$, and $0.8 \%$ at yrs $1-5$, respectively).
Safety. The IR of overall AE, including SAE, infections, serious infections, and autoimmune events, in the cumulative study period relative to the DB treatment period are provided in Table 1. SAE were reported for 250 patients in the 5-year cumulative study period (DB plus LTE periods), at an incidence rate of 13.87 events/100 patient-years. The types of AE occurring during the LTE for patients originally randomized to $\mathrm{ABA}$ were similar to those during the $\mathrm{DB}$ period, as reported ${ }^{3,6}$.

Nineteen deaths among ABA-treated patients were reported in total during the cumulative study period, 17 of which occurred during the LTE. These included 2 events that were considered by the investigators as probably related to the study drug: acute lymphocytic/lymphoblastic leukemia (ALL) and reoccurrence of lower lobe pneumonia; and 2 events considered possibly related: septic shock due to an infected wound received during a fall, and lung cancer. In addition, the following events were reported: 3 cardiac arrests and 1 event each of myocardial infarction, cardiac failure, retroperitoneal bleed/hypovolemic shock, myocardial ischemia with postoperative complications, neuroendocrine carcinoma of malignant lung (non-small cell origin), stroke, irreversible cardiogenic shock, hypoxia with metastatic melanoma, ruptured aortic aneurysm, and severe respiratory failure.

During the cumulative study period, infections were reported in 487 patients, at an IR of 67.14 events/100 patient-years, and serious infections in 64 patients, at an IR of 2.84 events/100 patient-years (Table 1). The most common infections (occurring in $>5 \%$ of patients) were nasopharyngitis (IR: 8.65), upper respiratory tract infection (8.02), urinary tract infection (6.46), bronchitis (5.80), influenza (4.25), pharyngitis (4.11), sinusitis (3.47), gastroenteritis (2.31), rhinitis (2.24), and oral herpes (1.35). There were few cases of opportunistic infections throughout the cumulative study period. Two cases of pulmonary tuberculosis (TB) in ABA-treated patients have been described through 3 years of the AIM study ${ }^{3,6}$; subsequently, an

Table 1. Safety summary.

\begin{tabular}{lcc}
\hline & $\begin{array}{c}\text { Double-blind Period, } * \\
\text { ABA Group } \\
(1 \mathrm{yr} ; \mathrm{n}=433) \\
\text { Incidence rate (events/100 patient-yrs) }\end{array}$ & $\begin{array}{c}\text { Cumulative Period },^{\dagger} \\
\text { All ABA-treated Patients } \\
\text { (5 yrs; } \mathrm{n} \text { (10) }\end{array}$ \\
\hline Adverse events & 303.4 & 242.32 \\
Serious adverse events & 17.7 & 13.87 \\
Infections & 90.5 & 67.14 \\
Serious infections & 4.2 & 2.84 \\
Malignancies & 1.7 & 1.45 \\
Autoimmune events & 2.5 & 0.99 \\
\hline
\end{tabular}

*Data are for patients randomized to abatacept during the double-blind period. ${ }^{\dagger}$ Data are for all patients who had received at least 1 dose of abatacept in the double-blind or longterm extension period, regardless of treatment group during the double-blind period. ABA: abatacept.

Personal non-commercial use only. The Journal of Rheumatology Copyright $@$ 2014 . All rights reserved. 
additional case was reported in a 64-year-old man originally randomized to ABA (enrolled in Europe). The patient tested positive for Mycobacterium tuberculosis, experienced episodes of asthma, fever, dyspnea, and thoracic pain, and began anti-TB treatment. The event was considered serious and the study drug was discontinued. A fourth patient (54-year-old man; enrolled in Europe) who discontinued the study as a result of serious pleural effusion (resolved with treatment) was subsequently diagnosed with M.tuberculosis and received anti-TB treatment. No further information regarding this patient was available.

Two patients (enrolled in Mexico) experienced protozoal infections (amoebic colitis and amoebic dysentery, neither considered serious). There were 11 parasitic infestations overall, none of which were considered severe or serious: acarodermatitis $(\mathrm{n}=5)$; parasitic infection $(\mathrm{n}=2)$; and acariasis, blastocystitis, malaria, and urogenital trichomoniasis ( $\mathrm{n}=1$ for each).

Malignancies were reported in 28 patients in the LTE. These included basal cell carcinoma in 11 patients, squamous cell carcinoma in 6 patients ( 3 of which were of the skin and 2 of which were in patients who also had basal cell carcinoma), prostate cancer in 2 patients, malignant lung cancer in 2 patients, and 1 event each of ALL, bronchioloalveolar carcinoma, colon cancer (in 1 patient who also had basal cell carcinoma), endometrial cancer, extranodal marginal zone B cell lymphoma [mucosa-associated lymphoid tissue (MALT) type], lymphoma, malignant melanoma in situ, metastatic malignant melanoma, myelodysplastic syndrome, and metastatic neoplasm and neuroendocrine carcinoma of non-small cell origin of malignant lung (in 1 patient). The cases of malignant lung cancer, prostate cancer, lymphoma, bronchioloalveolar carcinoma, extranodal marginal zone B cell lymphoma MALT type, metastatic neoplasm, neuroendocrine carcinoma, basal cell carcinoma, squamous cell carcinoma, colon cancer, metastatic melanoma, and endometrial cancer resulted in discontinuation; all other events resolved with treatment.

Autoimmune events occurred in 49 patients at an IR of 0.99 events/100 patient-years during the cumulative period, the most common (in $\geq 3$ patients) of which were psoriasis $(\mathrm{n}=17)$; vasculitis $(\mathrm{n}=7)$; sicca syndrome $(\mathrm{n}=4)$; and erythema nodosum, keratoconjunctivitis sicca, Sjögren syndrome, and increased antinuclear antibody count $(\mathrm{n}=3$ for each); these were not considered serious and were of mild or moderate intensity. During the LTE, 2 patients experienced autoimmune events of severe intensity (systemic lupus erythematosus and dermatomyositis).

Acute infusional AE (within $1 \mathrm{~h}$ after the start of infusion) were reported in 30 patients during the LTE. The events that occurred in more than 1 patient were hypertension $(n=8)$; headache $(n=7)$; infusion-site extravasation $(n=5)$; infusion-site swelling and increased blood pressure
( $\mathrm{n}=4$ for each); and decreased blood pressure, dizziness, and tachycardia ( $\mathrm{n}=2$ for each).

Clinical efficacy. For patients continuing treatment, the overall proportions of patients achieving ACR 20,50, and 70 responses following 1 year of $\mathrm{DB}$ ABA treatment remained consistent through to Year 5 (Figure 2A). In posthoc analyses of patients in the LTE who achieved an ACR 20 response at Year 1 and for whom data were available at other timepoints, 93.3\% (265/284) maintained an ACR 20 response up to Year 2, 90.7\% (233/257) up to Year 3, 95.5\% (232/243) up to Year 4, and 90.6\% (202/223) up to Year 5. Further, 69.4\% (197/284) of Year 1 ACR 20 responders went on to achieve an ACR 50 response at Year 2, and 43.9\% (125/285) achieved ACR 70 at Year 2. These responses were also maintained over time, with $73.3 \%$ (189/258), 75.3\% (183/243), and 67.1\% (151/225) of Year 1 ACR 20 responders achieving ACR 50 at years 3, 4, and 5 and $43.3 \%(113 / 261), 49.0 \%(119 / 243)$, and $45.8 \%$ (103/225) achieving ACR 70 at years 3,4, and 5. Of patients who continued treatment at Year 5, 113/157 (72.0\%) and 62/99 (62.6\%) patients had sustained an ACR 50 or ACR 70 response, respectively, from Year 1 to 5. Mean (SD) change in DAS28-CRP from baseline at Year $1[-2.83(0.07), \mathrm{n}=$ 365] was sustained at Year 5 [-3.14 $(0.08), \mathrm{n}=264]$. The overall proportions of patients who achieved DAS28-CRP scores of $\leq 3.2$ and $<2.6$ during the 1 -year DB period were also maintained over 5 years for those continuing to take ABA treatment (Figure 2B). In posthoc analyses of patients who still received the treatment at Year 5, 94/132 (71.2\%) and 47/78 (60.3\%) patients had sustained DAS28-CRP scores of $\leq 3.2$ and $<2.6$, respectively.

HAQ-DI score decreased from $1.68(0.63)$ at baseline to $1.00(0.68)$ at Year $1(\mathrm{n}=369)$; reductions in HAQ-DI score were maintained through Year 5 [0.92 (0.68), $\mathrm{n}=271]$. Mean (SE) changes in HAQ-DI score from baseline were also sustained from Year $1[-0.68(0.03)]$ to Year $5[-0.77$ (0.04)]. At Year 1, 116/369 patients (31.4\%) achieved normalization of HAQ-DI (HAQ-DI $\leq 0.5$ ). In posthoc analyses of patients who continued with treatment at Year 5, $66 / 89(74.2 \%)$ sustained a normalized HAQ-DI response from years 1-5.

Posthoc analyses investigating the proportions of patients simultaneously experiencing multiple measures of disease activity demonstrated that $85 / 199$ patients $(42.7 \%)$ achieved both an ACR 50 response and DAS28-CRP score of $<2.6$, and 78/199 (39.2\%) achieved both an ACR 50 and HAQ normalization at Year 1; responses were maintained at Year 5 in 80/164 (48.8\%) and 70/165 (42.4\%) patients, respectively. Additionally, 109/167 patients (65.3\%) achieved both an ACR 50 and radiographic nonprogression at Year 1, and these responses were maintained in 67/146 (45.9\%) at Year 5 of ABA treatment.

For patients originally randomized to placebo who switched to ABA treatment during the LTE, improvements

Personal non-commercial use only. The Journal of Rheumatology Copyright $(\odot) 2014$. All rights reserved. 
A)

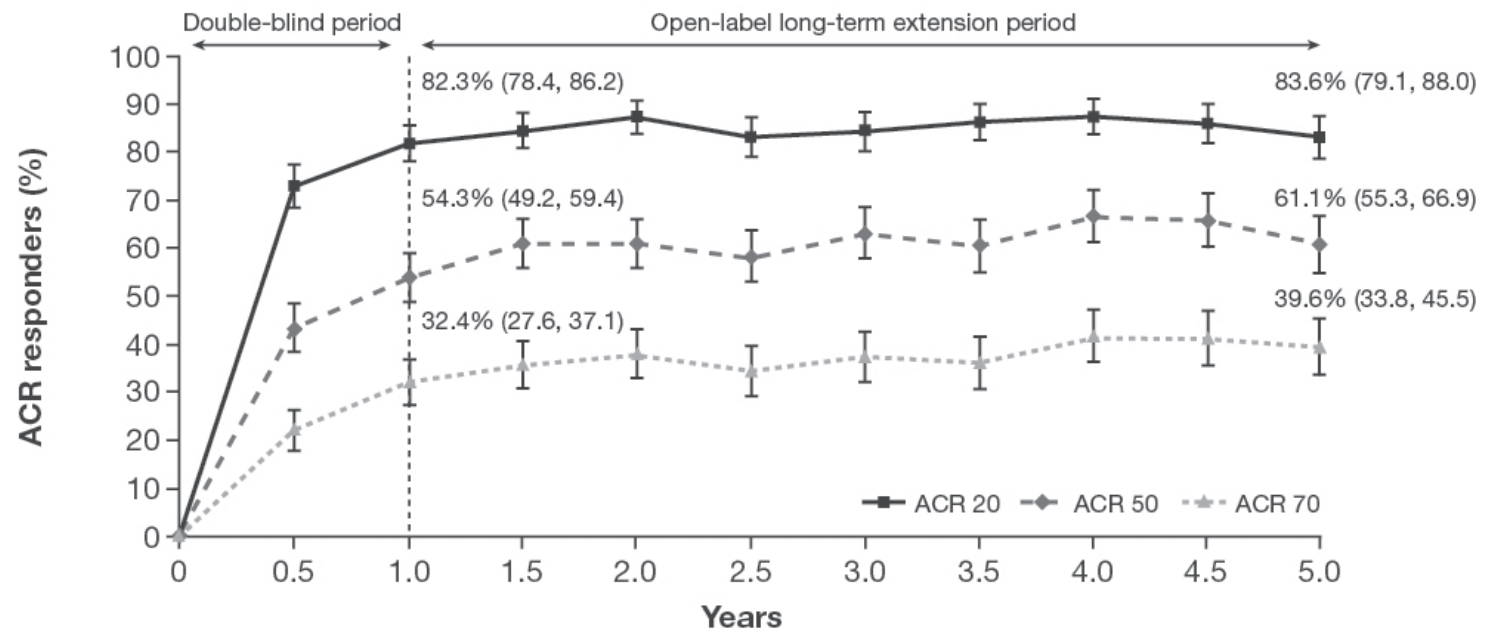

Number of patients included in the analysis ( $n$ )

\begin{tabular}{ccccccccccc}
\hline & Month & Year & Year & Year & Year & Year & Year & Year & Year & Year \\
& 6 & 1 & 1.5 & 2 & 2.5 & 3 & 3.5 & 4 & 4.5 & 5 \\
\hline ACR 20 & 371 & 373 & 353 & 337 & 311 & 303 & 289 & 288 & 273 & 268 \\
ACR 50 & 373 & 372 & 348 & 338 & 314 & 306 & 289 & 288 & 274 & 270 \\
ACR 70 & 374 & 374 & 350 & 340 & 314 & 309 & 289 & 288 & 278 & 270 \\
\hline
\end{tabular}

B)

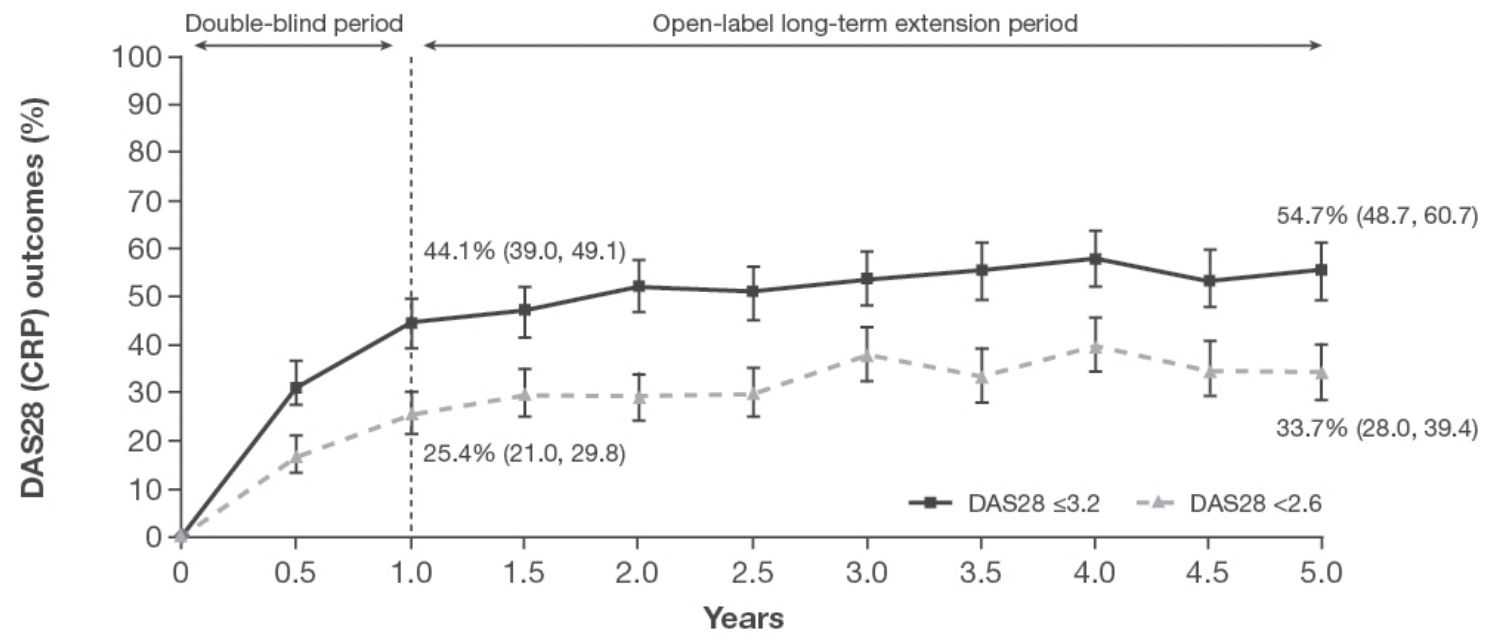

Number of patients included in the analysis ( $n$ )

\begin{tabular}{ccccccccccc}
\hline & Month & Year & Year & Year & Year & Year & Year & Year & Year & Year \\
& 6 & 1 & 1.5 & 2 & 2.5 & 3 & 3.5 & 4 & 4.5 & 5 \\
\hline DAS28 $\leq 3.2$ & 371 & 370 & 343 & 337 & 303 & 299 & 267 & 284 & 269 & 267 \\
DAS28 $<2.6$ & 371 & 370 & 343 & 337 & 303 & 299 & 267 & 284 & 269 & 267 \\
\hline
\end{tabular}

Figure 2. Percentages of (A) ACR 20,50, and 70 responders, and (B) patients with DAS28-CRP $\leq 3.2$ or $<2.6$ during 5 years. Data are for all patients originally randomized to abatacept who entered the longterm extension, with data available at the visit of interest (as-observed population), and are presented with $95 \%$ CI within parentheses. Both double-blind (Day 1 to Year 1) and longterm extension (yrs 1-5) data are presented. ACR: American College of Rheumatology; CRP: C-reactive protein; DAS28: 28-joint Disease Activity Score. 
in clinical efficacy were observed over their 4 years of treatment. The proportions of patients achieving ACR 20, 50 , and 70 responses following 1 year of DB placebo treatment were $54.1 \%$ (86/159), 25.0\% (40/160), and 8.8\% (14/160). After switching to ABA in the LTE, rates of ACR 20, 50, and 70 responses increased to $83.0 \%$ (122/147), $63.3 \%$ (93/147), and 33.3\% (49/147) at Year 2; responses were maintained with continued treatment. Similarly, the proportions of patients in the placebo group who achieved DAS28-CRP scores of $\leq 3.2$ and $<2.6$ during the 1 -year DB period (11.9\% and $2.5 \%$, respectively) increased after patients switched to ABA (Year 2, 52.0\% and 30.4\%) and were maintained with continued treatment (Year 5, 58.5\% and $38.2 \%$ ). During the LTE, mean changes in HAQ-DI score from baseline in the original placebo group also increased to levels that were comparable with the original ABA group, and were maintained over time [mean (SE) change in HAQ-DI score from baseline, ABA vs placebo: Year $1,-0.68(0.03)$ vs $-0.51(0.05)$; Year $2,-0.74(0.04)$ vs -0.72 (0.06); Year 5, -0.77 (0.04) vs $-0.72(0.06)]$.

Radiographic progression. At years 1-5, a total of 291, 290, 293, 287, and 235 patients, respectively, had radiographs available for assessment. For patients originally randomized to $\mathrm{ABA}$, reductions in the rate of structural damage progression seen following initiation of $\mathrm{ABA}$, as assessed by mean changes from baseline in Genant-modified Sharp scores, were maintained with continued longterm treatment for patients who continued with therapy (Figure 3).

Among patients originally randomized to ABA, 59.5\% (95\% CI 53.8\%-65.1\%) showed no radiographic progression after Year 1. The overall proportion of patients demonstrating no radiographic progression was maintained over the LTE (Figure 4A). For patients with no radiographic progression in the preceding years, $75.6 \%, 88.5 \%, 91.9 \%$, and $97.5 \%$ remained nonprogressors at years $2-5$, respectively (Figure 4B). In posthoc analyses of patients who continued with treatment at Year 5, 100/139 (71.9\%) patients sustained radiographic nonprogression from Year 1 to 5 .

For patients originally randomized to placebo who switched to ABA treatment during the LTE, reduced radiographic progression was also observed over 4 years following $\mathrm{ABA}$ initiation (radiographic nonprogression: Year 2, 48.8\%; Year 3, 44.3\%; Year 4, 42.5\%; Year 5, $39.1 \%)$.

\section{DISCUSSION}

The LTE of the AIM study evaluated the longterm safety, radiographic benefits, and clinical efficacy of $\mathrm{ABA}$ treatment in patients with RA and an inadequate response to MTX. Discontinuation in the AIM trial was consistent over 5 years of treatment, and overall results demonstrate that longterm ABA was well tolerated in this population, providing sustained clinical and radiographic benefit.
Further, the safety of ABA, in combination with MTX, was consistent over 5 years, with no increase in the IR of overall $\mathrm{AE}, \mathrm{SAE}$, infections, serious infections, and autoimmune events in the cumulative study period, and no unexpected events in the LTE, relative to the DB period. These findings reflect previous assessments of the longterm safety profiles of other biologics in patients with RA, which have demonstrated similar results ${ }^{14,15,16,17 .}$

Changes to concomitant MTX, steroids, and nonbiologic DMARD were permitted from Month 6 of our study. Despite this, mean MTX and steroid doses remained stable over time, and few patients added other DMARD, suggesting that longterm treatment with ABA plus MTX was well tolerated and efficacious. The fact that concomitant medication use, including steroids, remained relatively consistent throughout this longterm trial is perhaps reflective of the nature of the patient population enrolled in our study (patients with longstanding, established moderate to severe disease).

Patients with RA have an increased risk of infection, and certain malignancies may be further increased during treatment with biologic agents ${ }^{18,19,20,21,22}$; an increased risk of opportunistic infections has been reported with MTX and low-dose prednisone ${ }^{23}$. In our study, the IR of serious infection in the cumulative ABA experience is at the lower end of the range observed in patients with RA treated with other biologics (IR: 1.60-6.42 events/100 patient-yrs) ${ }^{24,25,26,27}$. Further, the IR of serious infection was not increased in the cumulative ABA experience compared with the DB period, with relatively few patients experiencing opportunistic infections such as TB or protozoal infections. This is consistent with findings from an integrated analysis of safety with IV ABA in the pooled clinical trial program (including the AIM trial), which included 4149 IV ABA-treated patients with 12,132 patient-years of exposure over up to 8 years' treatment ${ }^{28}$. In that analysis, the annual IR for hospitalized infection remained stable with increasing exposure, when evaluated at yearly intervals. In the current study, the IR of malignancies with ABA did not increase in the cumulative period relative to the DB period, suggesting no increase in risk with increasing exposure. This is also consistent with data from the integrated safety analysis, in which the annual IR of malignancies did not increase with increasing exposure to $\mathrm{ABA}^{28}$. Autoimmune events occurred at an IR of 0.99 events/ 100 patient-years, which is consistent with the IR reported in the integrated safety summary (1.99/100 patient-yrs ${ }^{28}$. Similarly, the IR of acute infusional events were similar between the DB and cumulative periods. ABA has been shown to have a stable longterm safety profile with consistently low incidence rates of serious infections, malignancies, and autoimmune events $^{29,30}$.

Progressive structural damage in patients with RA is associated with increasing functional disability over time,

Personal non-commercial use only. The Journal of Rheumatology Copyright ( $\subset$ 2014. All rights reserved. 
A)

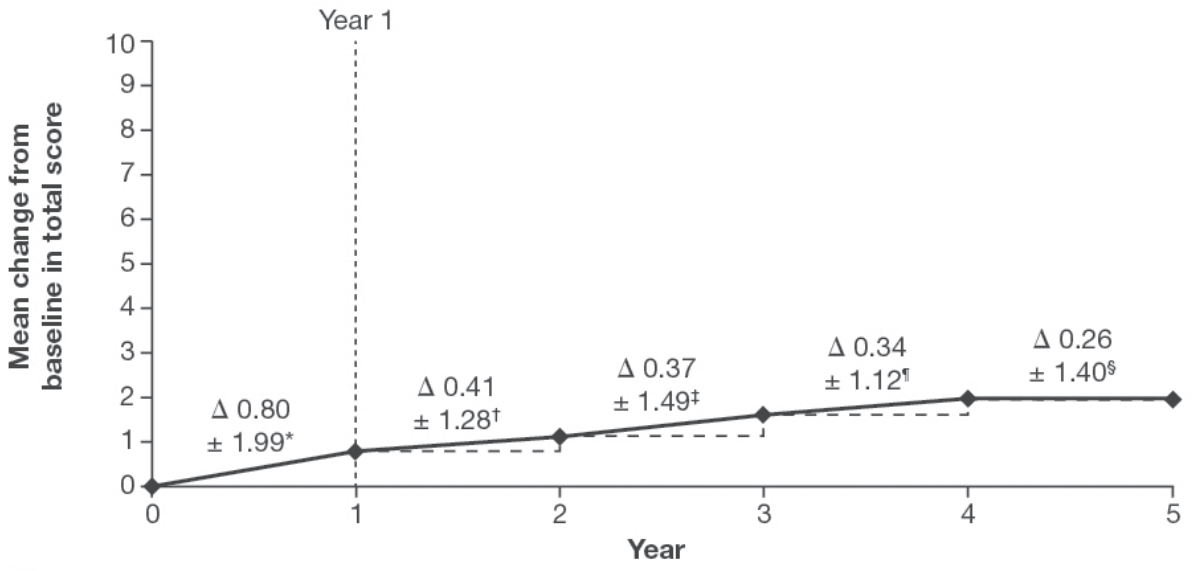

B)

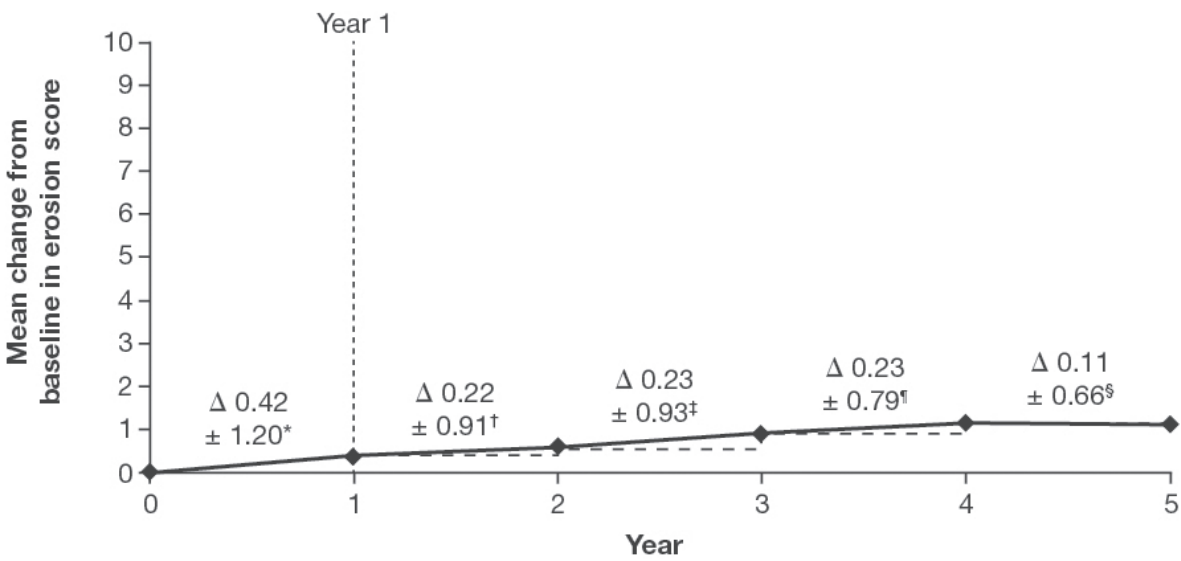

C)

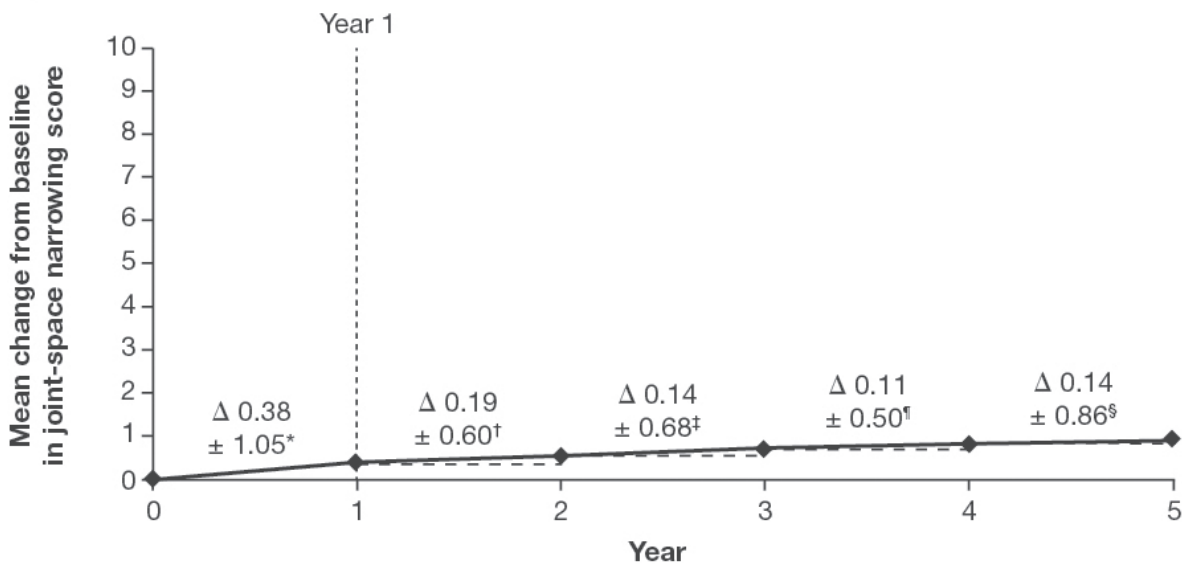

\begin{tabular}{|c|c|c|c|c|c|}
\hline & $\begin{array}{c}\text { BL } \\
\text { to Year } 1\end{array}$ & $\begin{array}{c}\text { Year } 1 \\
\text { to Year } 2\end{array}$ & $\begin{array}{c}\text { Year } 2 \\
\text { to Year } 3\end{array}$ & $\begin{array}{c}\text { Year } 3 \\
\text { to Year } 4\end{array}$ & $\begin{array}{l}\text { Year } 4 \\
\text { to Year } 5\end{array}$ \\
\hline $\begin{array}{l}\text { Abatacept-treated } \\
\text { patients included } \\
\text { in assessment }(\mathrm{n})\end{array}$ & 291 & 290 & 293 & 290 & 233 \\
\hline
\end{tabular}

Figure 3. A. Change from baseline in Genant-modified Sharp total score. B. Erosion score. C. Joint-space narrowing score in patients originally randomized to abatacept (ABA) and entering the longterm extension. Data are presented for patients originally randomized to ABA who entered the longterm extension with available assessments at the visit of interest (as-observed population). *Baseline to Year 1 ; ${ }^{\dagger}$ Year 1 to Year 2 ; ${ }^{\ddagger}$ Year 2 to Year $3 ;{ }^{\mathfrak{I}}$ Year 3 to Year $4 ;{ }^{\S}$ Year 4 to Year 5. $\Delta$ : change from previous year (mean \pm SD); BL: baseline. 


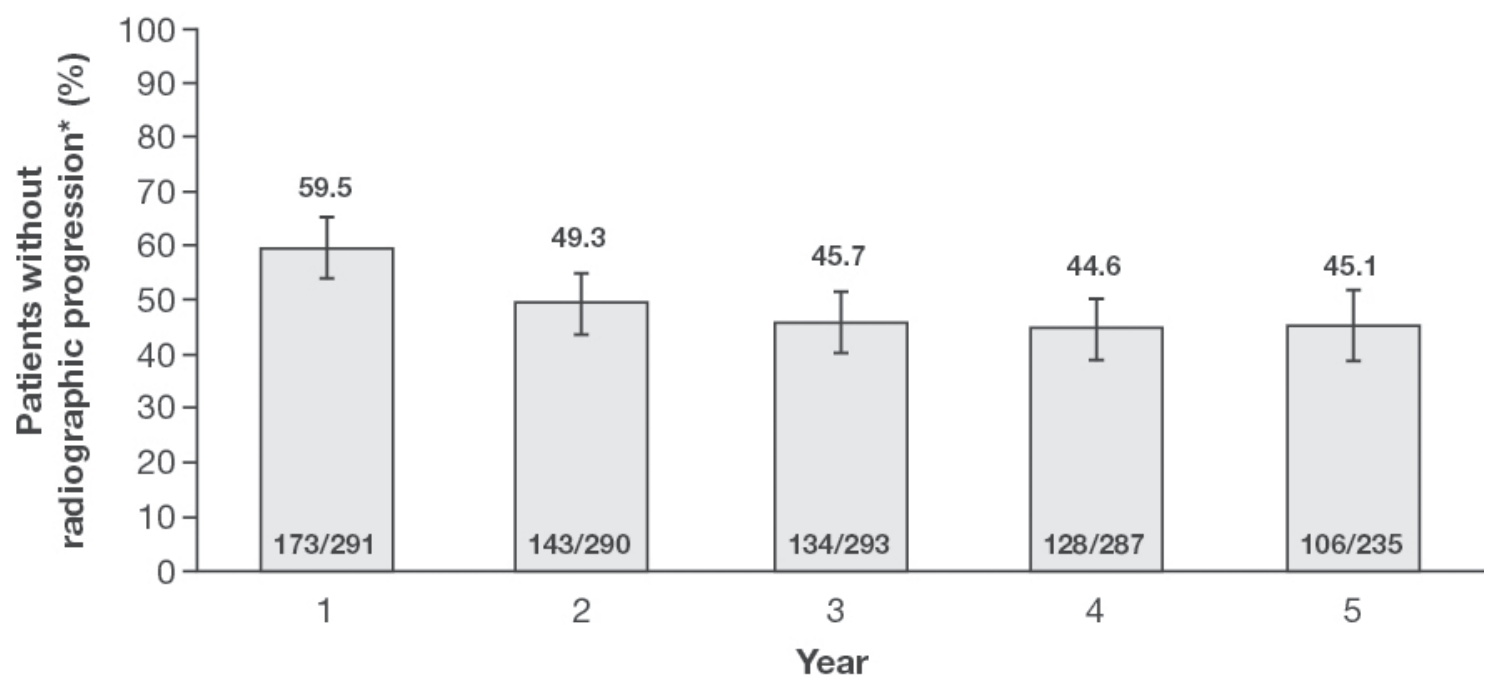

B)

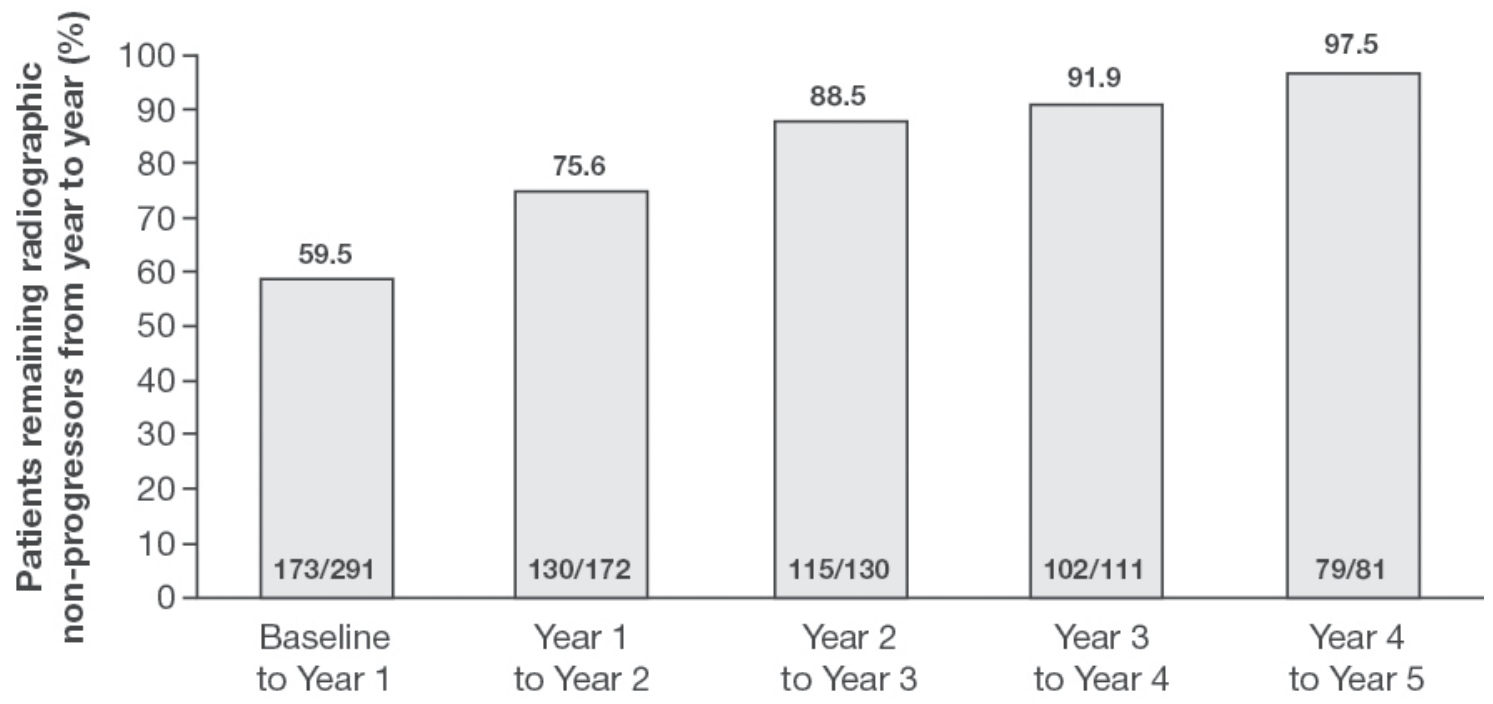

Figure 4. Radiographic disease progression over 5 years of abatacept (ABA) treatment. A. Proportion of patients without radiographic progression* in each year. B. ABA-treated patients who remained nonprogressors from years 1 to 5 . Error bars represent $95 \%$ CI. Data are presented for patients originally randomized to abatacept who entered the longterm extension and had evaluable radiographs available at the appropriate timepoints. *Nonprogression is defined as a change from baseline in radiographic total score of $\leq 0$.

mostly due to joint destruction $9,31,32$. In the AIM trial, treatment with $\mathrm{ABA}$ resulted in persistent radiographic inhibition over time, with almost half of all patients exhibiting no structural damage progression (change from baseline in TS of $\leq 0$ ) when assessed at each year during the 5-year study period. Nearly all patients who had no structural damage progression (according to this definition) from years 3-4 remained free from progression at Year 5.

Although remission is the primary goal for clinicians treating RA, this target can be challenging in patients with longstanding disease, and achieving low levels of disease activity can be considered an acceptable alternative treatment goal in these patients ${ }^{33}$. In addition to such improvements in disease activity, enhancing physical function should be an important treatment goal. Treatment with ABA provided improvements in the signs and symptoms of RA, disease activity, and physical function that were sustained over 5 years for patients who continued taking the treatment. Posthoc analyses of patient-level data demonstrated that many patients who had achieved clinical

Personal non-commercial use only. The Journal of Rheumatology Copyright () 2014. All rights reserved. 
efficacy, radiographic nonprogression, and normalized physical function at Year 1 had sustained these responses at Year 5 if they continued the treatment. Posthoc analyses also investigated the proportions of patients who simultaneously achieved multiple measures of disease activity. These analyses were designed to determine whether patients demonstrating "improvements" in signs and symptoms were also attaining target clinical and functional outcomes. These data showed that, at Year 5, almost half of the ABA-treated ACR 50 responders also achieved a DAS28-CRP $<2.6$, or had also experienced HAQ normalization.

Patients with RA who are treated with biologic DMARD often discontinue treatment because of the chronic and longterm nature of RA therapies; retention rates reported in longterm studies are of particular clinical interest, because they provide an indication of the likelihood of patients to continue treatment in clinical practice ${ }^{34}$. About $70 \%$ of patients who entered the LTE were still participating after 5 years of ABA treatment in the AIM trial. Annual discontinuation rates generally decreased over each year of the study, with few discontinuations owing to lack of efficacy $(<3.0 \%$ each year). The annual retention rates and discontinuations owing to efficacy/safety reasons demonstrate that over time, fewer patients discontinued therapy because of loss of efficacy or occurrence of safety events. This supports the sustainability of longterm efficacy seen in many patients and the consistent safety of ABA over time.

Longterm extension studies provide a valuable opportunity to evaluate safety and the IR of AE; however, certain limitations, as outlined by Buch, et $a l^{35}$, should be taken into consideration when interpreting clinical and radiographic efficacy data from such trials. Data from AIM were based on as-observed analyses, which are vulnerable to patient discontinuation. Patients who do respond are likely to remain in the study, and patients who do not are likely to discontinue, resulting in a potentially reduced denominator over time and bias toward responders at later timepoints. However, the availability of radiographs from a large proportion of trial patients and the relatively low discontinuation rate in our study suggest that the radiographic and clinical efficacy data presented here are generally representative of the patient population in our study. These data should be evaluated based on the objective of evaluating the structural and clinical effects of $\mathrm{ABA}$ in patients who continue the treatment. In addition, these data were obtained in a clinical trial setting, and so caution should be used when considering these findings in relation to clinical practice. Strict inclusion and exclusion criteria mean that patients treated in clinical trials often have a higher disease burden than patients in the clinic. The findings from the AIM trial should be considered within the context of its design limitations.

Overall, treatment with ABA over a period of 5 years was generally well tolerated. It demonstrated sustained clinical benefits with regard to the signs and symptoms of RA, disease activity, and physical function, and provided consistent structural benefits over time. Along with a high patient retention rate, these data support the longterm use of $\mathrm{ABA}$ in patients with RA who have an inadequate response to MTX.

\section{REFERENCES}

1. Aletaha D, Landewe R, Karonitsch T, Bathon J, Boers M, Bombardier C, et al. Reporting disease activity in clinical trials of patients with rheumatoid arthritis: EULAR/ACR collaborative recommendations. Ann Rheum Dis 2008;67:1360-4.

2. Kremer JM, Dougados M, Emery P, Durez P, Sibilia J, Shergy W, et al. Treatment of rheumatoid arthritis with the selective costimulation modulator abatacept: twelve-month results of a phase IIb, double-blind, randomized, placebo-controlled trial. Arthritis Rheum 2005;52:2263-71.

3. Kremer JM, Genant HK, Moreland LW, Russell AS, Emery P, Abud-Mendoza C, et al. Effects of abatacept in patients with methotrexate-resistant active rheumatoid arthritis: a randomized trial. Ann Intern Med 2006;144:865-76.

4. Schiff M, Keiserman M, Codding C, Songcharoen S, Berman A, Nayiager S, et al. Efficacy and safety of abatacept or infliximab vs placebo in ATTEST: a phase III, multi-centre, randomised, double-blind, placebo-controlled study in patients with rheumatoid arthritis and an inadequate response to methotrexate. Ann Rheum Dis 2008;67:1096-103.

5. Kremer JM, Genant HK, Moreland LW, Russell AS, Emery P, Abud-Mendoza C, et al. Results of a two-year followup study of patients with rheumatoid arthritis who received a combination of abatacept and methotrexate. Arthritis Rheum 2008;58:953-63.

6. Kremer JM, Russell AS, Emery P, Abud-Mendoza C, Szechinski J, Westhovens R, et al. Long-term safety, efficacy and inhibition of radiographic progression with abatacept treatment in patients with rheumatoid arthritis and an inadequate response to methotrexate: 3-year results from the AIM trial. Ann Rheum Dis 2011;70:1826-30.

7. Schiff M, Keiserman M, Codding C, Songcharoen S, Berman A, Nayiager S, et al. Clinical response and tolerability to abatacept in patients with rheumatoid arthritis previously treated with infliximab or abatacept: open-label extension of the ATTEST Study. Ann Rheum Dis 2011;70:2003-7.

8. Westhovens R, Kremer JM, Moreland LW, Emery P, Russell AS, Li $\mathrm{T}$, et al. Safety and efficacy of the selective costimulation modulator abatacept in patients with rheumatoid arthritis receiving background methotrexate: a 5-year extended phase IIB study. J Rheumatol 2009;36:736-42.

9. Genant HK, Peterfy CG, Westhovens R, Becker JC, Aranda R, Vratsanos G, et al. Abatacept inhibits progression of structural damage in rheumatoid arthritis: results from the long-term extension of the AIM trial. Ann Rheum Dis 2008;67:1084-9.

10. Felson DT, Anderson JJ, Boers M, Bombardier C, Furst D, Goldsmith C, et al. American College of Rheumatology. Preliminary definition of improvement in rheumatoid arthritis. Arthritis Rheum 1995;38:727-35.

11. Fransen J, van Riel PL. The Disease Activity Score and the EULAR response criteria. Rheum Dis Clin North Am 2009; 35:745-57.

12. Pincus T, Summey JA, Soraci SA Jr., Wallston KA, Hummon NP. Assessment of patient satisfaction in activities of daily living using a modified Stanford Health Assessment Questionnaire. Arthritis Rheum 1983;26:1346-53.

13. Genant HK, Jiang Y, Peterfy C, Lu Y, Redei J, Countryman PJ. Assessment of rheumatoid arthritis using a modified scoring method on digitized and original radiographs. Arthritis Rheum

Personal non-commercial use only. The Journal of Rheumatology Copyright @ 2014 . All rights reserved. 
1998;41:1583-90.

14. Klareskog L, Gaubitz M, Rodriguez-Valverde V, Malaise M, Dougados M, Wajdula J. A long-term, open-label trial of the safety and efficacy of etanercept (Enbrel) in patients with rheumatoid arthritis not treated with other disease-modifying antirheumatic drugs. Ann Rheum Dis 2006;65:1578-84.

15. Vander Cruyssen B, Van Looy S, Wyns B, Westhovens R, Durez P, Van den Bosch F, et al. Four-year follow-up of infliximab therapy in rheumatoid arthritis patients with long-standing refractory disease: attrition and long-term evolution of disease activity. Arthritis Res Ther 2006;8:R112.

16. Vander Cruyssen B, Durez P, Westhovens R, De Keyser F. Seven-year follow-up of infliximab therapy in rheumatoid arthritis patients with severe long-standing refractory disease: attrition rate and evolution of disease activity. Arthritis Res Ther 2010;12:R77.

17. Weinblatt M, Keystone E, Furst D, Kavanaugh A, Chartash E, Segurado O. Long term efficacy and safety of adalimumab plus methotrexate in patients with rheumatoid arthritis: ARMADA 4 year extended study. Ann Rheum Dis 2006;65:753-9.

18. Bongartz T, Sutton AJ, Sweeting MJ, Buchan I, Matteson EL, Montori V. Anti-TNF antibody therapy in rheumatoid arthritis and the risk of serious infections and malignancies: systematic review and meta-analysis of rare harmful effects in randomized controlled trials. JAMA 2006;295:2275-85.

19. Furst DE. Serum immunoglobulins and risk of infection: how low can you go? Semin Arthritis Rheum 2009;39:18-29.

20. Kroesen S, Widmer AF, Tyndall A, Hasler P. Serious bacterial infections in patients with rheumatoid arthritis under anti-TNF-alpha therapy. Rheumatology 2003;42:617-21.

21. Listing J, Strangfeld A, Kary S, Rau R, von Hinueber U, Stoyanova-Scholz M, et al. Infections in patients with rheumatoid arthritis treated with biologic agents. Arthritis Rheum 2005;52:3403-12.

22. Smitten AL, Simon TA, Hochberg MC, Suissa S. A meta-analysis of the incidence of malignancy in adult patients with rheumatoid arthritis. Arthritis Res Ther 2008;10:R45.

23. Greenberg JD, Reed G, Kremer JM, Tindall E, Kavanaugh A, Zheng $\mathrm{C}$, et al. Association of methotrexate and tumour necrosis factor antagonists with risk of infectious outcomes including opportunistic infections in the CORRONA registry. Ann Rheum Dis 2010;69:380-6.

24. Askling J, Dixon W. The safety of anti-tumour necrosis factor therapy in rheumatoid arthritis. Curr Opin Rheumatol 2008; 20:138-44

25. Komano Y, Tanaka M, Nanki T, Koike R, Sakai R, Kameda H, et al. Incidence and risk factors for serious infection in patients with rheumatoid arthritis treated with tumor necrosis factor inhibitors: a report from the Registry of Japanese Rheumatoid Arthritis Patients for Longterm Safety. J Rheumatol 2011;38:1258-64.

26. van Dartel SA, Fransen J, Kievit W, Flendrie M, den Broeder AA, Visser $\mathrm{H}$, et al. Difference in the risk of serious infections in patients with rheumatoid arthritis treated with adalimumab, infliximab and etanercept: results from the Dutch Rheumatoid Arthritis Monitoring (DREAM) registry. Ann Rheum Dis 2013;72:895-900.

27. Widdifield J, Bernatsky S, Paterson JM, Gunraj N, Thorne JC, Pope $\mathrm{J}$, et al. Serious infections in a population-based cohort of 86,039 seniors with rheumatoid arthritis. Arthritis Care Res 2013; 65:353-61.

28. Weinblatt ME, Moreland L, Westhovens R, Cohen RB, Kelly SM, Khan $\mathrm{N}$, et al. The safety of abatacept administered intravenously in the treatment of rheumatoid arthritis: integrated analyses of up to 8 years of treatment from the abatacept clinical trial program. J Rheumatol 2013;40:787-97.

29. Hochberg MC, Westhovens R, Aranda R, Kelly SM, Khan N, Qi K. Long-term safety of abatacept: integrated analysis of clinical program data of up to 7 years of treatment. Arthritis Rheum 2010;62 Suppl 10:S164.

30. Singh JA, Christensen R, Wells GA, Suarez-Almazor ME, Buchbinder R, Lopez-Olivo MA, et al. Biologics for rheumatoid arthritis: an overview of Cochrane reviews. Cochrane Database Syst Rev 2009;CD007848.

31. Scott DL, Pugner K, Kaarela K, Doyle DV, Woolf A, Holmes J, et al. The links between joint damage and disability in rheumatoid arthritis. Rheumatology 2000;39:122-32.

32. Welsing PM, van Gestel AM, Swinkels HL, Kiemeney LA, van Riel PL. The relationship between disease activity, joint destruction, and functional capacity over the course of rheumatoid arthritis. Arthritis Rheum 2001;44:2009-17.

33. Smolen JS, Aletaha D, Bijlsma JW, Breedveld FC, Boumpas D, Burmester G, et al. Treating rheumatoid arthritis to target: recommendations of an international task force. Ann Rheum Dis 2010;69:631-7.

34. Alarcon GS, Tracy IC, Blackburn WD Jr. Methotrexate in rheumatoid arthritis. Toxic effects as the major factor in limiting long-term treatment. Arthritis Rheum 1989;32:671-6.

35. Buch MH, Aletaha D, Emery P, Smolen J. Reporting of long-term extension studies: lack of consistency calls for consensus. Ann Rheum Dis 2011;70:886-90. 